\title{
A biblioteca de Osman Lins no IEB/USP e na Fundação Casa de Rui Barbosa
}

\author{
[ The Osman Lins library in IEB/USP and in Casa de Rui Barbosa Foundation
}

\section{Eder Rodrigues Pereira ${ }^{\mathrm{I}}$}

\begin{abstract}
Este texto é excerto modificado da tese Da leitura à escritura - a biblioteca de Osman Lins como parte do processo de criação de Avalovara, apresentada ao Programa de Pósgraduação em Teoria Literária e Literatura Comparada da Faculdade de Filosofia, Letras e Ciências Humanas da USP, sob orientação da profa. dra. Sandra Margarida Nitrini e coorientação da profa. dra. Telê Ancona Lopez.
\end{abstract}

RESUMO - Depositada no Instituto de Estudos Brasileiros da Universidade de São Paulo e na Fundação Casa de Rui Barbosa, a biblioteca de Osman Lins conta com 282 livros. Como leituras declaradas, algumas obras guardam, enquanto documento arquivístico, a consolidação de um momento da criação. Desse modo, este artigo apresenta uma descrição da biblioteca como parte do processo criador do escritor pernambucano, visualizando que as anotações, grifos ou apontamentos de leitura se convertem em manuscrito, reforçando a importância da abordagem dos documentos do processo e a presença de um diálogo intertextual. · PALAVRAS-CHAVE - Biblioteca de escritor; processo criador; Osman Lins. .

\begin{abstract}
Deposited in the Institute for Brazilian Studies of the University of São Paulo and in the Casa de Rui Barbosa Foundation, the Osman Lins' library is composed by 282 books. As declared readings, some works keep, while archival documents, the consolidation of a moment of creation. Thus, this article presents a description of the library as part of the creative process of the Pernambuco writer, visualizing that the annotations, highlights or reading notes are converted into manuscript, reinforcing the importance of approaching the documents of the process and the presence of an intertextual dialogue. - KEYWORDS - Writer's library; creative process; Osman Lins.
\end{abstract}

Recebido em 4 de janeiro de 2016

Aprovado em I5 de fevereiro de 2017

PEREIRA, Eder Rodrigues. A biblioteca de Osman Lins no IEB/USP e na Fundação Casa de Rui Barbosa. Revista do Instituto de Estudos Brasileiros, Brasil, n. 66, p. 86-I07, abr. 2017.

DOI: http://dx.doi.org/Io.II606/issn.23I6-90IX.voi66p86-I07

I Universidade de São Paulo (USP, São Paulo, SP, Brasil). 
A maior parte da documentação resultante da vida e da obra de Osman Lins, após a morte do autor, ficou aos cuidados da esposa, a escritora Julieta de Godoy Ladeira. A partir de então, ela ampliou o arquivo com reportagens, artigos, dissertações e teses. Manteve contato com os amigos e editores, concentrando esforços na divulgação do trabalho de seu companheiro. Além disso, fez novas edições de livros esgotados e organizou a correspondência trocada por Osman Lins e Hermilo Borba Filho numa coletânea inédita cujo título é E viva a vida! Correspondência entre escritores ${ }^{2}$.

Para preservar esse material, Julieta de Godoy Ladeira dividiu a documentação em dois conjuntos e formalmente os doou ao Instituto de Estudos Brasileiros da Universidade de São Paulo (IEB/USP) e ao Arquivo-Museu de Literatura Brasileira (AMLB) da Fundação Casa de Rui Barbosa, "provavelmente como estratégia para alcançar maior difusão", conforme Marisa Balthasar Soares³. No entanto, mesmo diante de um arquivo extremamente rico, trabalhar com esse espólio significa também lidar com lacunas e questões que talvez não sejam respondidas.

Os principais problemas residem no fato de que a divisão em dois núcleos impede observá-lo como um todo, traçar uma linha histórica precisa e até mesmo confrontar documentos. Com isso, ao não encontrar algo no IEB, supõe-se que esteja na Casa de Rui Barbosa e vice-versa. Uma solução seria a digitalização do acervo, porém, no

2 Essa correspondência com 99 cartas de Osman Lins para Hermilo Borga Filho e 89 cartas deste para Osman Lins faz parte de um dossiê que está no Fundo Osman Lins IEB/USP, caixa Io, documentos OL-RS-DVV-oooI a OL-RS-DVV-ooI4. Além da edição, encontra-se o projeto do livro, versões do prefácio, reportagens sobre os escritores, biografias e a correspondência de Julieta de Godoy Ladeira com a agência literária Carmen Balcells, que intermediou a publicação com a Cia. das Letras. A editora recusou a publicação por achar o gênero comercialmente inviável. Sob os cuidados de Nelson Luís Barbosa, com supervisão do prof. dr. Marcos Antonio de Moraes, desenvolve-se o projeto de pós-doutorado O diálogo epistolar entre Osman Lins e Hermilo Borba Filho. Ver: < http://www.ieb.usp.br/o-dialogo-epistolar-entre-osman-lins-e-hermilo-borba-filho >. Acesso em: jan. 20I7.

3 SOARES, Marisa Balthasar. No arquivo do artesão. Cult, julho de 200I, p. 62. 
contato com os arquivos, nota-se que muitos documentos estão fora desses espaços de preservação4.

Alguns exemplos dessa dispersão estão na correspondência de Osman Lins com os amigos Zila Mamede, Alexandrino E. Severino, Magno Montez, Laís Corrêa de Araújo e Lauro de Oliveira, em que há comentários sobre rascunhos, planos e originais enviados para apreciação. Em carta de 22 de novembro de I960, Lins cita a Zila Mamede a bolsa de estudos que recebera da Aliança Francesa de Paris e fala sobre a publicação de $O$ fiel e a pedra, reforçando que ainda não havia decidido se lhe enviaria os originais da obra: "Acho besteira isto de você querer guardá-los. Mas também (vaidadezinha escondida) ainda não me decidi a rasgá-los”.

A questão que fica é se Osman Lins realmente enviou os originais à amiga ou se os rasgou, visto que eles não são localizados no IEB nem na Casa de Rui Barbosa. Contudo, trabalhar com arquivos significa também lidar com vazios e ausência de informações. Certas questões podem ter resposta com a descoberta de um novo documento ou até mesmo ficar sem explicação devido à perda, à destruição ou dispersão do material. Um arquivo que é constituído fundamentalmente por elementos textuais deve levar em consideração a biblioteca do escritor como componente, pois sobre sua importância Telê Ancona Lopez argumenta que:

As bibliotecas de escritores têm se mostrado de capital interesse para a compreensão dos caminhos tomados por poetas, ficcionistas, críticos ou jornalistas. Como somatório de títulos, contribuem para a história da leitura; como espaço da criação, ligam-se implícita ou explicitamente à gênese de obras, ao nos propor matrizes e, na marginália, materializam instantes da escritura. Conservadas ou não no seio de acervos completos, isto é, conjugadas a arquivos, coleções - de quadros, discos, filmes ou de objetos diversos -, essas bibliotecas, quando mantêm cadernos de registro ao longo da chegada de livros e periódicos, ou selos, carimbos de livrarias e faturas de compra, historiam fases da própria formação $0^{6}$.

Desse modo, em uma biblioteca de escritor percebe-se a constituição variada de títulos e seções sobre uma área restrita ou em outras que interessam às suas obsessões. Sobre esse assunto, o aporte teórico e metodológico tem se ampliado nos últimos anos, principalmente, no campo da genética textual. Erica Durante, a partir de um levantamento das contribuições relevantes, comenta o trabalho Marginalia - readers writing in books, de Heather J. Jackson, e o volume Bibliothèques d'écrivains, dirigido por Paolo D’Iorio e Daniel Ferrer. Já no campo das obras catalogadas e dos

4 Uma compreensão sobre a teoria do arquivo, do ponto de vista da arquivologia, pode ser encontrada em: BELLOTTO, Heloísa Liberalli. Arquivo: estudos e reflexões. Belo Horizonte: UFMG, 20I4. Contudo, o arquivo pode ser observado a partir da questão do esquecimento, tendo como livro teórico: DERRIDA, Jacques. Mal de arquivo - uma impressão freudiana. I. ed. Trad. Claudia de Moraes Rego. Rio de Janeiro: Relume-Dumará, 2001.

5 Fundo Osman Lins IEB/USP - Documento: OL-RS-CA-ooIo.

6 LOPEZ, Telê Ancona. A criação literária na biblioteca do escritor. Ciência e cultura, revista da SBPC, v. 59, n. I, jan.-mar. 2007, p. 33 . 
estudos sobre bibliotecas de escritor, menciona os trabalhos de Telê Ancona Lopez, precursora nas investigações sobre a biblioteca de Mário de Andrade, o catálogo Samuel Beckett's Library, publicado por Marc Nixon e Dirk Van Hulle, e o estudo A biblioteca particular de Fernando Pessoa, feito por Pizarro, Ferrari e Cardiello. Além disso, Durante salienta, brevemente, que isso não se restringe apenas às estantes dos escritores, existindo um alargamento dessa perspectiva sobre a biblioteca de artistas, filósofos e cientistas, reforçando então que a anatomia de uma biblioteca de escritor:

[...] se presenta como híbrida, al esta constituida por material impreso (los libros) y manuscritos (las marcas y anotaciones de lectura), que, además de una tipología claramente distinta de soportes, supone una proveniencia doble, ya que, en un mismo cuerpo de papel, el libro, coexisten un primer autor, el que escribió y que ahora es leído, y otro autor, que es el que lee, y al leer escribe. En este espacio que Daniel Ferrer, uno de los teóricos más lucidos de los estudios genéticos de bibliotecas de escritores, define "espacio de transición en el que interactúan livros y manuscritos, y en cual la escritura in fieri va tomando forma en lo ya escrito" la cuestión de la autografía, y por ende de la autoría resulta florante. Así, además de la hibridez, también hay cierta promiscuidad que caracteriza este lugar de "transición" y de interacción que es la biblioteca de escritor.

Interacción, por no decir, fagocitación, ya que, en el marco limitado del libro impreso, el lector autor, al leer a otro autor, se vuelve provisoriamente un "escritor de marginalia", según lo define muy justamente Heather Jackson hablando de Coleridge. Este lector especial que es el autor, se vuelve escritor de marginalia, en la medida en que aplica al libro sus operaciones usuales de escritura, aísla segmentos de texto, extrapola, copia, a veces traduce [...] Físicamente, la biblioteca se presenta como una entidad múltiple e irregular, compuesta de contenidos y formatos heterogéneos, que además, está en movimiento constante (nuevas adquisiciones, intercambios, préstamos, pérdidas y desplazamientos). Virtualmente, también la biblioteca de un escritor plantea la misma fluctuación por ausencia de límites?.

Contudo, essa abordagem não é recente, já que em I963 Antonio Candido inaugurou na USP um projeto que propôs o estudo da marginália nos livros e revistas da biblioteca de Mário de Andrade, resultando assim em três dissertações: O se-sequestro da dona ausente: reconstrução de um estudo de Mário de Andrade a partir de suas notas de leitura (I967), de Telê Ancona Lopez, Leituras em francês de Mário de Andrade (I967), de Nites Feres, e Mário de Andrade e L'esprit Nouveau (I968), de Maria Helena Grembecki ${ }^{8}$.

Em relação à biblioteca de Osman Lins, mesmo diante de inúmeras referências citadas por ele, poucos livros foram preservados, restando I80 no IEB/USP e IO2

7 DURANTE, Erica. La biblioteca de escritor frente al mundo global: repensar un método a partir de R. Piglia,

D. Link y R. Fresán. Manuscrítica - revista de crítica genética, São Paulo, n. 24, 20I3, p. 23.

8 LOPEZ, Telê Ancona. Os manuscritos no arquivo e na biblioteca de Mário de Andrade. In: NITRINI, Sandra

(Org.). Tessituras, interações, convergências. I. ed. São Paulo: Hucitec/Abralic, 20II, p. 423-424. 
volumes na Casa de Rui Barbosa9. Porém, refletir sobre essas obras não significa que as edições depositadas são necessariamente leituras consolidadas, e tampouco uma edição antiga significa leitura antiga. As datas nos dão um trajeto das possíveis pesquisas realizadas pelo escritor, auxiliando na visualização de determinado momento da gênese ${ }^{\text {Io }}$.

Assim sendo, parte dessas leituras está diretamente ligada à construção de algumas obras, seja pela aproximação de temas, conteúdos ou pela presença de marginália. Portanto, como leituras declaradas esses livros guardam, enquanto documento arquivístico, um instante da criação. Pode-se, então, pensar na dificuldade e até mesmo na impossibilidade de analisar todo esse material devido ao fato de que a biblioteca, além de abarcar obras que refletem amplo campo de escolha, conta com a dispersão de volumes que seriam primordiais para observar certos procedimentos adotados por Lins. Faço então inicialmente uma reflexão geral sobre a biblioteca preservada no IEB/USP e na Casa de Rui Barbosa, tecendo relações e aproximações, para mostrar, tanto quanto possível, como certas leituras estão atreladas à formação ou são parte de uma produção literária do autor para, em seguida, destacar alguns aspectos quanto às obras que se dispersaram.

9 A relação dos livros está na tese que desenvolvi sobre o romance Avalovara. Nesse trabalho, aprofundei-me na análise da marginália na biblioteca pessoal do autor, ali captando momentos vinculados ao diálogo intertextual e a apropriação, importantes tanto para crítica genética como para a literatura comparada. Assim, reflexões mais amplas foram desenvolvidas em: Pereira, Eder Rodrugues. Da leitura à escritura -a biblioteca de Osman Lins como parte do processo criador de Avalovara. Tese (Doutorado em Teoria Literária e Literatura Comparada). Faculdade de Filosofia, Letras e Ciências Humanas, Universidade de São Paulo, São Paulo, 20I5, 589f.

Io A questão da leitura pode ser explorada em diversas perspectivas. Em A literatura e o leitor: textos de estética da recepção, temos uma compreensão da produção, recepção e comunicação, relação complexa entre autor, obra e público. LIMA, Luiz Costa (org.). A literatura e o leitor: textos de estética da recepção. Rio de Janeiro: Paz e Terra, I979. Apropriando-se de parte desses conceitos, Renata Rocha Ribeiro desenvolveu o estudo: RIBEIRO, Renata Rocha. Leitura e escrita na narrativa de Osman Lins. Tese (Doutorado em Estudos Literários). Faculdade de Letras, Universidade Federal de Goiás. Goiânia, 20Io, 269f. Contudo, a linha teórica adotada neste trabalho leva em consideração o posicionamento de Almuth Grésillon em "Ler para escrever": "Mas o scriptor não lê apenas para encontrar informações precisas, preencher lacunas da memória, determinar a situação histórica ou geográfica, verificar a exatidão dos conhecimentos que deseja empregar ou pôr em questão? Estaremos tão certos de que o gesto do "ler para escrever" é apanágio dos textos com valor informativo, documental e científico? A leitura não é também um formidável motor para pôr em movimento o imaginário, para fazer sonhar assim como para fazer saber, para desencadear associações verbais e visuais, que transformarão a fonte lida em pedaços de escrita, o fragmento de outrem em enunciado novo?”. GRÉSILLON, Almuth. Ler para escrever. Escritos - Revista da Fundação Casa de Rui Barbosa, ano 5, n. 5, $20 I I$. 


\section{A biblioteca PRESERVADA ${ }^{11}$}

Há na literatura de Osman Lins uma intensificação da intersecção entre a poética e a arte pictórica. Para Ermelinda Araújo Ferreira essa questão revela-se um dos aspectos mais curiosos da produção osmaniana, visto que "pintura, escultura, tapeçaria, geometria e ornamentalismo são temas frequentes em seus textos, que se notabilizam por explorar exaustivamente os limites entre a palavra e a imagem"г2. Nesse sentido, não é difícil verificar na biblioteca obras que contemplam esses assuntos.

Sobre pintura há livros relacionados a um movimento específico ou a pintores, títulos como La peinture italienne - du Caravage a Modigliani (I952), de Lionello Venturi e Rosabianca Skira-Venturi, Marc Chagall (I953), de Godo Remszhardt, Impressionist paintings in the Louvre (I96I), de Germain Bazin, Miró (I967), de Jacques Dupin, Giovanni Bellini (I968), de Fred Gettings, e Maneirismo - o mundo como labirinto (I974), de Gustav R. Hoche.

A arquitetura surge nos títulos Les châteaux de la Loire (I957), de François Gebelin, Padoue: guide artistique illustré avec la plante des monuments (I958), de Sandro Chierichetti, Les bâtisseurs des cathédrales (I958), de Jean Gimpel, Saint-Étienne de Bourges - architecture et vitraux (I960), de André Chichereau, e Quadro da arquitetura no Brasil (I970), de Nestor Goulart Reis Filho.

Reflexões sobre arte e estética estão em Contribution à l'esthétique (I953), de Henri Lefebvre, A revolução da arte moderna (I955), de Hans Sedlmayr, Problemática da estética e a estética fenomenológica (I958), de Moritz Geiger, Páginas de estética contemporânea (I966), de Pierre Abraham, A necessidade da arte (I966), de Ernest Fischer, e As origens da forma na arte (I967), de Herbert Read.

II O termo "preservado" relaciona-se aos livros que estão sob guarda do IEB/USP e na Fundação Casa de Rui Barbosa. Nesse sentido, a noção de preservação entra em consonância com pressupostos da arquivologia, que relaciona esse material ao acúmulo natural, criando assim um fundo, elemento oposto à ideia de coleção. Já o conceito de (des)construção/dispersão pode ser vislumbrado, em outra perspectiva, no fragmento "Desempacotando a minha biblioteca", de Walter Benjamin. BENJAMIN, Walter. Desempacotando a minha biblioteca. In: . Rua de mão única. I. ed. Trad. João Barrento. São Paulo: Autêntica, 20 I3.

I2 FERREIRA, Ermelinda Maria Araújo. Cabeças compostas - a personagem feminina na narrativa de Osman Lins. 2. ed. São Paulo: Edusp, 2005, p. 29. 

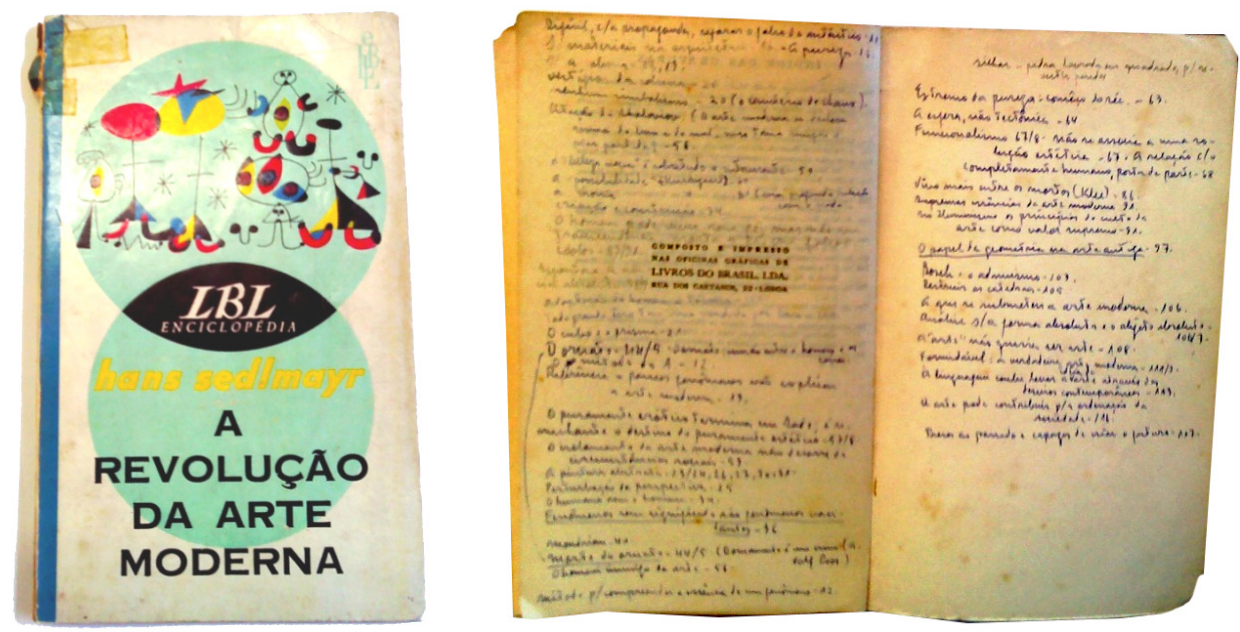

Figura I - Livro de Hans Sedlmayr em apontamentos da leitura de Osman Lins

Esse conjunto de livros sobre pintura, arquitetura e estética convalida pela marginália em diversos títulos o interesse de Osman Lins por diferentes áreas, abrindo, portanto, frentes de análise para compreender a intersecção de sua produção com esses ramos do conhecimento. A fortuna crítica do autor já observou parte dessas relações, enfatizando principalmente o ornamentalismo em sua obra, porém Ermelinda Araújo Ferreira pontua que:

[...] pesquisas mais amplas sobre a presença das prováveis origens desses modelos ainda se fazem necessárias, pois a natureza dessas transposições, de tão complexa e de efeitos tão surpreendentes, não só renova o gênero romanesco como aponta, provavelmente, para o mais efetivo, criativo e bem-acabado exercício sinestésico de que se terá conhecimento na literatura de língua portuguesa ${ }^{\mathrm{T} 3}$.

Nessa direção, Elisabete Marin Ribas tece, em sua dissertação Giz, caneta e pincel: literatura e história da arte nas aulas do professor Osman Lins ${ }^{\mathrm{I} 4}$, diversas considerações que contribuem para a elucidação dessa interface entre literatura e outras artes ao analisar, planos de aula de literatura, teoria literária, teatro e relatórios acadêmicos, documentos esses depositados no IEB/USP, referentes ao período em que Lins atuou como docente de Literatura Brasileira na Faculdade de Filosofia, Ciências e Letras de Marília. Mostra que Osman Lins, preocupado com o nível do conhecimento das artes dos alunos, montou um curso de História da Arte. Além de estabelecer relações

I3 Ibidem, p. I9.

I4 RIBAS, Elisabete Marin. Giz, caneta e pincel: literatura e história da arte nas aulas do professor Osman Lins. Dissertação (Mestrado em Teoria Literária e Literatura Comparada). Faculdade de Filosofia, Letras e Ciências Humanas, Universidade de São Paulo, São Paulo, 20I2, I94f. 
pertinentes do tema com a produção osmaniana, a autora recompõe esse curso por meio da transcrição de aulas gravadas de fitas cassete, vinculadas à reprodução de imagens em slides e referências ausentes na biblioteca pessoal do escritor.

Contudo, ao se agruparem os livros em unidades temáticas, encontram-se argumentos para reforçar a ideia de que esses núcleos se ligam ao modo de Lins formar sua matéria ou repertório intelectual. Mas até que ponto sustenta-se esse conceito? Será que realmente a biblioteca preservada no arquivo tem conexões com a literatura do autor? Ademais, diante de tantos livros perdidos, como afirmar que essas leituras têm relação com seu processo criador? A resposta para as questões parece ter fundamentação em outro conjunto temático com 23 livros examinados para a composição do romance inacabado A cabeça levada em triunfo. Este, por sua vez, teria nascido de um pacto firmado entre Hermilo Borba Filho e Osman Lins, movido por histórias e lendas sobre Lampião e seu bando, sendo que entre elas se destaca aquela da cabeça de cangaceiro negociada na Estação de Palmares. Os escritores desejavam cada um a seu modo transfigurar esse caso em literatura. Borba Filho não começou o livro, relatando o fato no romance "A margem das lembranças, resolvido, porém, insatisfatoriamente" "I. Lins não terminou a obra, mas deixou documentos valiosos, como uma versão inacabada, notas de planejamento e seu diário da doença com informações sobre o texto ${ }^{\mathrm{I}}$.

I5 MOURA, Ivana. Osman Lins: o matemático da prosa. I. ed. Recife: Fundação de Cultura do Recife, 2003, p. 92. I6 Foi desenvolvido entre 2012 e 20I4 o projeto de pós-doutorado A cabeça levada em triunfo, de Osman Lins estabelecimento do texto e estudo genético, de Francisco José Gonçalves Lima Rocha, sob a supervisão da profa. dra. Telê Ancona Lopez. Rocha trabalhou com esses documentos depositados no IEB/USP e na Casa de Rui Barbosa, considerando ainda parte dessas leituras como referência para composição do romance inacabado. 


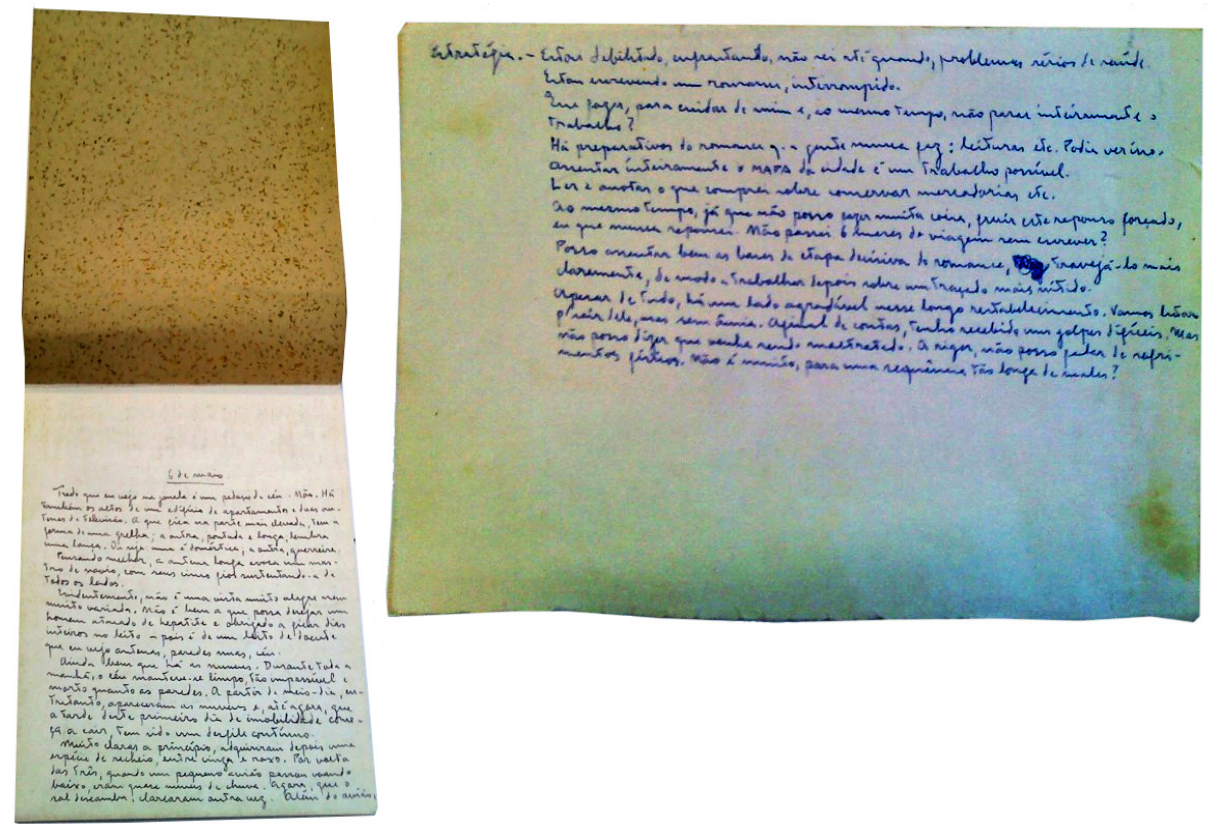

Figura 2 - Diário da doença e nota de planejamento, documentos com informações sobre A cabeça levada em triunfo

Nos livros vinculados à composição de A cabeça levada em triunfo, os temas predominantes são o cangaço e a flora com os títulos. Estas são as obras: Lampião (I975) e Sinhô Pereira (I975), de Nertan Macedo, Cangaceiros e fanáticos (I976), de Rui Facó, Caçadores de cabeças (I976), de Marcus Cláudio Acquaviva, Os cangaceiros (I977), de Maria Isaura Pereira de Queiroz, Curiosidades de nossa flora (I956), de Getúlio César, Como vivem as plantas (I970), de Johannes van Overbeek, Conheça a vegetação brasileira (I970), de Aylthon Brandão Joly, Plantas e flores ornamentais para sua casa e jardim (I975) e Horticultura (I977), de Irineu Fabichak.

Mas também se encontram obras literárias em torno do universo regionalista, como Trepandé (I972), de Plínio Salgado, Estória de engenho vol. II (I973), Universo verde (I975) e Estória de engenho vol. 20 (I976), de Claribalde Passos, bem como as que pontuam o contexto histórico-social: Juazeiro do padre Cícero (s/d), de Lourenço Filho, e A República Nova (I976), de Edgard Carone. Essas leituras, algumas com notas marginais, são documentos do processo e sistematizam aspectos importantes da criação, uma vez que se ligam ao modo como Osman Lins forma sua escrita. Elas relacionam-se a temas, motivos, tratamento do espaço ou ambiente, instaurando assim uma ampla rede intertextual. Essa prática, de acordo com Telê Ancona Lopez, destaca:

[...] a (re)criação que se afirma com originalidade e autonomia ao integrar outro contexto. Desse ponto de vista, as matrizes, consolidadas ou não pela marginália de 
um escritor, descobertas no circuito de um diálogo intertextual, interessam também à literatura comparada. Matrizes e marginália nos conduzem, por força da intertextualidade e da dimensão documentária, à tentativa de reconstruir, no diálogo, certas instâncias do ato criador enquanto conjunção de leitura e escritura, convergência na esfera intelectual; enquanto sutil passagem da recepção à criação ou alcance maior da recepção que, segundo Daniel Ferrer, se transforma em produção e se extrema na bricolagem. Diálogo, enquanto leitura anotada, implica movimento na pesquisa do artista que se desenrola em consonância com suas obsessões, reconhecíveis na obra; subentende crítica, seleção e assimilação ${ }^{\mathrm{I7}}$.

Dessa maneira, diante desse conjunto de livros na biblioteca de Osman Lins, percebe-se uma verdadeira cenografia da leitura que oferece pistas das operações de absorção e de como se constrói o empréstimo. Nesse sentido, ao pensar a criação como uma rede de conexões, como propõe Cecília Almeida Salles, nota-se a multiplicidade de relações, sendo que essa mesma rede aumenta sua complexidade à medida que se estabelecem novas direções. Assim, essa "visão do processo de criação nos coloca em pleno campo relacional, sem vocação para o isolamento de seus componentes, exigindo, portanto, permanente atenção à contextualização e ativação das relações que o mantêm como sistema complexo"ז8.

Ao associar, então, as obras presentes na biblioteca de Osman Lins com a produção dele, tem-se a possibilidade de trilhar vários caminhos e, levando-se em consideração determinadas declarações ou uma aproximação temática, há alguns livros ligados a Avalovara. Por exemplo, em carta a Nelly Novais Coelho, colega de magistério na Faculdade de Filosofia, Ciências e Letras de Marília, Lins comenta não apenas algumas dessas obras como também as relações delas com o romance. Cabe transcrever a carta, pois ela, como documento no arquivo da criação de Osman Lins, constitui uma substanciosa nota de planejamento, marcando o sentido de materiais e cores:

\section{S. Paulo, 2I de janeiro de I974}

Nelly,

Vão os artigos que pediu. Empresto também dois livros sobre ciências ocultas. Verá que o sinal gráfico que identifica o terceiro amor de Abel, longe de ser um capricho, constitui uma chave fundamental para a compreensão do romance.

Há toda uma temática do caos e da ordem (ligada ao problema da própria construção literária, que não é mais que a passagem do caos para o cosmos) atravessando o livro. A morte de Cecília, por exemplo, é a representação do caos. Todas as imagens ali expressas são imagens caóticas, de fim de ciclo. Cecília é uma anunciadora. Ver também que ela é sempre marcada por motivos metálicos. É bem clara, nesse sentido, a cena em que Abel a vê pela primeira vez, abrindo o portão de ferro, o vestido amarelo (ouro) etc. Os leões que a marcam e rodeiam também não são gratuitos. O Leão está

I7 LOPEZ, Telê Ancona, 2007, op. cit., p. 33.

I8 SALLES, Cecília Almeida. Redes da criação - construção da obra de arte. I. ed. São Paulo: Horizonte, 2006, p. 22. 
ligado à ideia de Ouro. Além disso, na história do tema O (Nascida e Nascida), vemos a heroína buscando o próprio nome, ou seja, buscando a própria identidade. Acha-a? Quem sabe? Dar-lhe um nome seria desencantá-la. Ver a esse respeito, as páginas I6 e I8 de La Palabra, de Georges Gusdorf, que também lhe empresto.Bem. Há uma infinidade de fios, alguns muito delicados, tecendo o nosso livro. Muitos, eu próprio já não sou capaz de identificar sem esforço - e talvez nem assim.

Conclua você como é estúpido, diante de objeto tão minuciosamente construído, e nutrido por antigos sonhos humanos, ditar apressadamente uma sentença que o liquida, como se se tratasse de algum brinquedo. Bem dizia Guimarães Rosa, falando de Literatura: “Tudo isso é muito sério e não pode ficar nas mãos de incapazes.”

Um abraço do

Osman Lins

P.S.- Os trechos de La Science Occulte que podem interessar-lhe vão marcados com tiras de papel. De Art e Alchimie, você poderá passar uma vista nas páginas II a 20. Já localizei acima o que há a ver no ensaio de G. Gusdorf.

O. L. ${ }^{\text {I9. }}$

Com alguns grifos nas páginas, La science occulte et les sciences occultes (I935), de Paul Carton, e Art e alchimie: étude de l'iconographie hermétique et de ses influences (I966), de J. Van Lennep, exibem parte da "infinidade de fios” à qual Osman Lins se refere. No que diz respeito ao tema da alquimia, a linguagem faz com frequência referências a símbolos astrológicos, metais, figuras enigmáticas, animais e ao uso de imagens sexuais. A essas duas referências expostas na carta, soma-se ainda o livro Trattato sulla pietra filosofale e l'arte dell'alchimia (I947), de São Tomás de Aquino, e nesse conjunto há outra unidade temática. Para Ana M. Alfonso Goldfarb as questões atreladas à alquimia sistematizam uma operação simbólica situada no plano cosmológico e "ligada aos anseios mais profundos da psique pela totalidade representada até nossos dias pelos símbolos mandalísticos que surgem em certos sonhos". Para a estudiosa, o alquimista "teria sido a figura que no passado melhor se sucedeu na busca à chamada 'individuação', ou autoconhecimento, através do qual o ser humano se integra ao cosmo" ${ }^{20}$. Na linguagem alquímica a relação ato amoroso e cosmogonia é representada pelo simbolismo da morte e do renascimento em que surgem opostos constantes como negativo e positivo, sombra e luz ou a passagem do Caos ao Cosmos. Porém, essa vasta simbologia liga-se também à "estrutura cósmica do ritual conjugal e do comportamento sexual dos seres humanos para representar

I9 Fundo Osman Lins IEB/USP - Documento: OL-RS-CA-0200.

20 GOLDFARB, Ana M. A. Da alquimia à química. I. ed. São Paulo: Nova Stella-Edusp, I987, p. 233. 
a cosmogonia"21. Tem-se, então, uma junção com outras obras que tratam da questão do ato amoroso, como Ananga-ranga: tratado hindu do amor conjugal (s/d), de Kalyana Malla, L'art amoureux des Indes (I957), de Max-Pol Fouchet, ou Estudios sobre el amor (I959), de José Ortega y Gasset. Além disso, o tema do zodíaco também faz parte das correlações simbólicas da alquimia, aumentando o entrelaçamento dos temas com os livros La religion astrale des pythagoriciens (I959), de Louis Rougier, e História breve da astrologia (I96I), de Paul Couderc.

Dessa maneira, essas referências tornam-se uma chave para a leitura de Avalovara, funcionando como fios internos que recompõem os diversos desdobramentos de significados da obra ao mesmo tempo que permitem a identificação dos elementos de continuidade, prolongamento e rupturas. Para seguir esse caminho, pode-se alinhar outras obras e pelo menos dois novos núcleos temáticos surgiriam, ampliando assim a rede de conexões. No primeiro, ao citar na carta La palabra (I957), de Georges Gusdorf, Osman Lins abre uma entrada para uma conexão de sua produção com leituras de crítica literária, mesmo afirmando que sua formação foi a de um apaixonado pela literatura. Com isso, diversos títulos presentificam um interesse pelos estudos literários, como Problemática de la literatura (I95I), de Guillermo Torre, Literatura europeia e Idade Média latina (I957), de Ernest Robert Curtius, Que peut la littérature? (I965), de Simone de Beauvoir, Théorie de la littérature - formalistes russes (I965), tradução para o francês de Todorov e Jakobson, Morphologie du conte - suivi de les transformations des contes merveilleux (I970), de Vladimir Propp, Signos em rotação (I972), de Octavio Paz entre outros.

Já no segundo núcleo, alinhado a textos literários, há realmente um pequeno recorte diante das inúmeras referências literárias que o autor deu em vida, havendo apenas II livros no Instituto de Estudos Brasileiro, entre eles alguns títulos da Coleção Nobel, como A fonte (I947), de Charles Morgan, O jovem José e José, o provedor (I948), de Thomas Mann. Na Fundação Casa de Rui Barbosa, entre I4 obras catalogadas, encontram-se Justine (I960), Balthazar (I96I), Clea (I96I) e Mountolive (I96I), conjunto que forma $O$ quarteto de Alexandria, de Lawrence Durrel, além de Vida e morte de M. J. Gonzaga de Sá (I970) e Recordações do escrivão Isaías Caminha, de Lima Barreto, objetos de estudo da tese de doutoramento de Osman Lins - Lima Barreto e o espaço romanesco ${ }^{22}$.

Portanto, na biblioteca preservada de Osman Lins repousa em algumas obras, sobretudo pela intervenção do grafite ou da caneta, uma leitura detida e cuidadosa

2I ELIADE, Mircea. O sagrado e o profano. 5. ed. Trad. Rogério Fernandes. São Paulo: Martins Fontes, 200I, p. I2I-I22.

22 Ao realizar seu estudo sobre Lima Barreto, Osman Lins preocupou-se com a construção do espaço na narrativa, sendo que duas formulações importantes, em nível teórico, aparecem em seu ensaio: a distinção entre espaço e ambientação e a sistematização da ambientação em três tipos (a franca, a reflexa e a dissimulada). Por sua vez, o romancista carioca teve interesse por bibliotecas, tema abertamente discutido em seu livro Diário de hospício. Não estabeleci essa relação no trabalho pelo fato de seguir uma dimensão documentária, ou seja, recompor a biblioteca e as possíveis leituras realizadas por Osman Lins. No entanto, esse paralelo é realizado em: ANTELO, Raul. Labirintos da biblioteca do pobre. Outra travessia, $\mathrm{I}^{0}$ semestre de 2015. 
na qual se percebe a pausa, a intercepção ocasional, e nesse procedimento observa-se um leitor que não se cala, um leitor que transforma o que é alheio em objeto seu, particular. Porém, longe de querer aproximar essas obras a temas ou a parte da produção artística e intelectual, algo que seria demasiadamente complexo e até mesmo impossível, parece certo afirmar que talvez esses livros tenham sido doados por Julieta de Godoy Ladeira pelo fato de neles existirem sinais de uma relação com o ato criador osmaniano, sendo possível verificar a partir de outros documentos a dispersão de certos títulos que passaram pelas mãos do escritor.

\section{UMA BIBLIOTECA PERDidA, UMA BIBLIOTECA (RE)CONSTRUídA}

Na recuperação das leituras realizadas por Osman Lins existe um jogo entre a "biblioteca preservada" - obras presentes no arquivo - e a "biblioteca declarada", que só seria recomposta se consideradas as diversas declarações do escritor. Nesse sentido, a citação valeria como uma leitura consolidada, o que permitiria uma análise ou relação a partir da observação dos elementos presentes no texto. Assim, após perceber em que nível ocorre a aproximação e o distanciamento, seria possível ver os pontos de contato ou simplesmente refutar tal ligação.

Nesse caso, não existiria a materialidade do livro na estante, por exemplo, aquele grifo que assinala um trecho ou até mesmo a prova da leitura efetivada. Porém, mesmo não sublinhando alguma frase ou a transpondo para uma folha como nota, a citação configura-se de certo modo como um ato de leitura, visto que desarticula o texto em sua integralidade e o transporta para outro contexto. Logo, "toda citação é primeiro uma leitura - assim como toda leitura, enquanto grifo, é citação” mesmo quando considerada no sentido mais banal ${ }^{23}$. Contudo, mesmo diante da ausência de algumas obras na "biblioteca preservada”, é possível pensar, a partir de outras evidências, numa (re)construção da "biblioteca perdida”, o que garante, em termos, uma visão do material disperso ou consultado por Osman Lins em outros espaços. Mas vale ressaltar que a destruição de um acervo é algo mais comum do que se imagina, pois "há mais bibliotecas destruídas do que reconstruídas" sem falar no fato de que a "ressurreição de uma biblioteca jamais pode ser sua reconstrução idêntica ao original", de acordo com Jean Marie Goulemot ${ }^{24}$.

Em relação à dispersão de alguns títulos que pertenceram a Lins, encontram-se no arquivo do IEB/USP I25 folhas de anterrosto com as dedicatórias de seus autores ou de amigos, sendo que em parte desses documentos não se identifica sequer o

23 COMPAGNON, Antoine. O trabalho da citação. I. ed. Trad. Cleonice P. B. Mourão. Belo Horizonte: Editora UFMG, 2007, p. I9.

24 GOULEMOT, Jean Marie. O amor às bibliotecas. I. ed. Trad. Maria Leonor Loureiro. São Paulo: Editora Unesp, 20Io, p. 60. 
título $^{25}$. Com isso, esse conjunto, além de indicar a ausência dos volumes, acentua uma rede de relações sociais constituída predominantemente no campo literário. Dentro dessa esfera de sociabilidade literária, Osman Lins recebeu dedicatória dos respectivos autores em Ninho das cobras, de Lêdo Ivo, Sol das almas, de Hermilo Borba Filho, Fenomenologia da obra literária, de Maria Luiza Ramos, Fernando Pessoa na África do Sul, de Alexandrino E. Severino, Texto/contexto, de Anatol Rosenfeld, As raízes existenciais da poesia bocagiana, de Nelly Novaes Coelho, A literatura brasileira - vol. V-o pré-modernismo, de Alfredo Bosi, Como aprendi o português e outras aventuras, de Paulo Rónai, Fundamentos da investigação literária, de Eduardo Portella, Os parceiros do Rio Bonito, de Antonio Candido, entre outros.

Porém, entre as várias folhas, a de Mythologie général $e^{26}$, publicação da Librairie Larousse sob a direção de Félix Guirand, com dedicatória de Lygia Fagundes Telles ${ }^{27}$. Nesse volume existe uma apresentação de mitos, lendas e histórias de diversas partes do mundo, incluindo as informações sobre a divindade oriental Avalokiteçvara, que serve de base para a composição do nome do romance, ideia da qual Osman Lins nunca fez segredo. Em entrevista a Geraldo Galvão Ferraz em 28 de novembro de I973 a explicação da origem do título se faz abertamente:

Veja - Você poderia dar uma visão geral de Avalovara, situando-o e apresentando-o ao leitor?

Lins - Primeiro, o título corresponde ao nome de um pássaro que existe no romance. Um pássaro imaginário. Inventei esse pássaro, não o nome. Pensava guardar para mim o segredo, mas revelo-o. Há uma divindade oriental, um ser cósmico, de cujos olhos nasceram o Sol e a Lua; de sua boca, os ventos; de seus pés, a Terra. Assim por diante. É lâmpada para os cegos, água para os sedentos, pai e mãe dos infelizes. Tem muitos braços, pois não lhe falta trabalho no mundo. Seu nome é Avalokiteçvara. Não foi difícil, aproveitando esse nome, chegar ao nome claro e simétrico de "Avalovara", que muitas pessoas acham estranho.

Veja - E qual o papel desse pássaro (ou desse deus) no romance?

Lins - Tem um papel simbólico. É um grande pássaro feito de pequenos pássaros. Simboliza este romance e também minha concepção de romance. Suas significações, porém, são ainda mais amplas. Por exemplo: o Avalokiteçvara é uma divindade plena

25 Esse material está depositado nas caixas 5 e 6 com uma classificação que vai de OL-RS-o043 a OL-RS-oI68. Dentro do possível, há informações sobre o nome dos autores, os livros e as datas das dedicatórias. Ao que tudo indica essas folhas de rosto foram destacadas e incorporadas aos demais documentos do arquivo, talvez por Julieta de Godoy Ladeira, porém os respectivos livros não se encontram na biblioteca de Osman Lins do IEB/USP ou da Fundação Casa de Rui Barbosa.

26 GUIRAND, Felix (Dir.). Mythologie générale. I. ed. Paris: Librairie Larousse, I935.

27 Fundo Osman Lins IEB/USP - Documento: OL-RS-0084. 
de amor. Tanto que, masculino na Índia, assume na China um caráter feminino, maternal ${ }^{28}$.

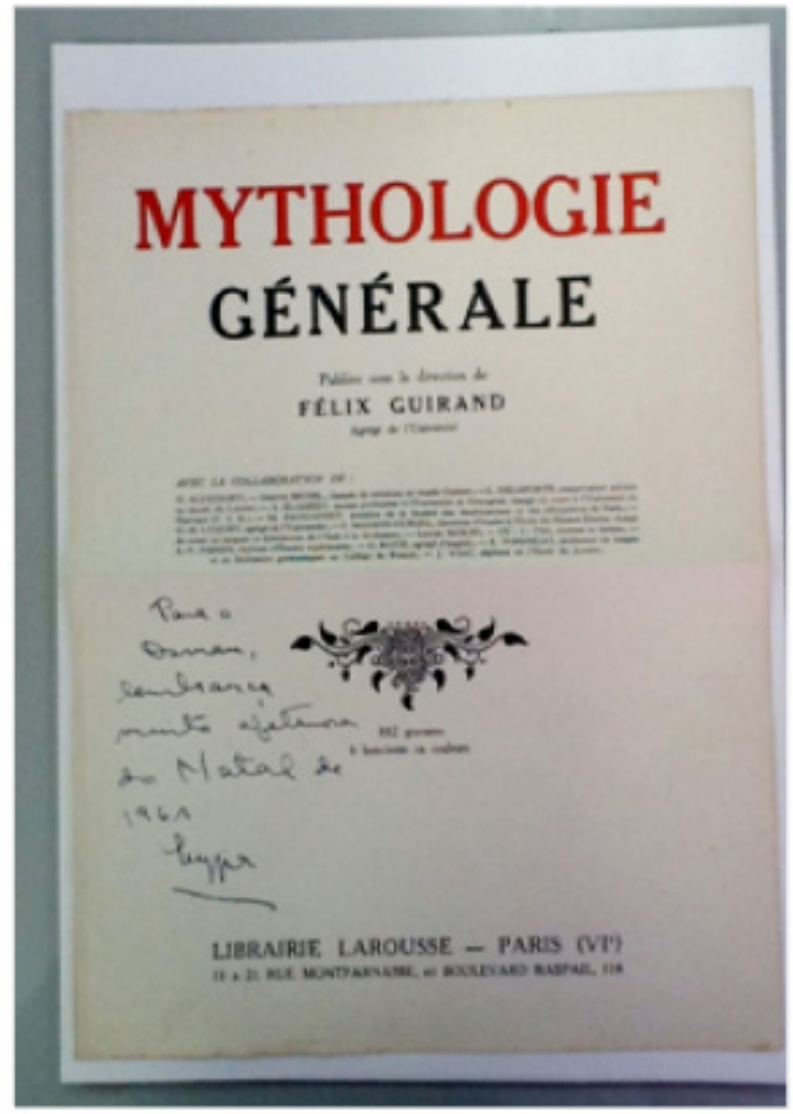

Figura 3 - Folha de rosto do livro Mythologie générale (direção de Félix Guirand), com dedicatória de Lygia Fagundes Telles

28 LINS, Osman. Escritor que se preza evita o poder. Entrevista a Veja em 28 de novembro de I973. In: Evangelho na taba - outros problemas inculturais brasileiros. I ${ }^{\mathrm{a}}$ ed. São Paulo: Summus Editorial, I979, p. I65. 

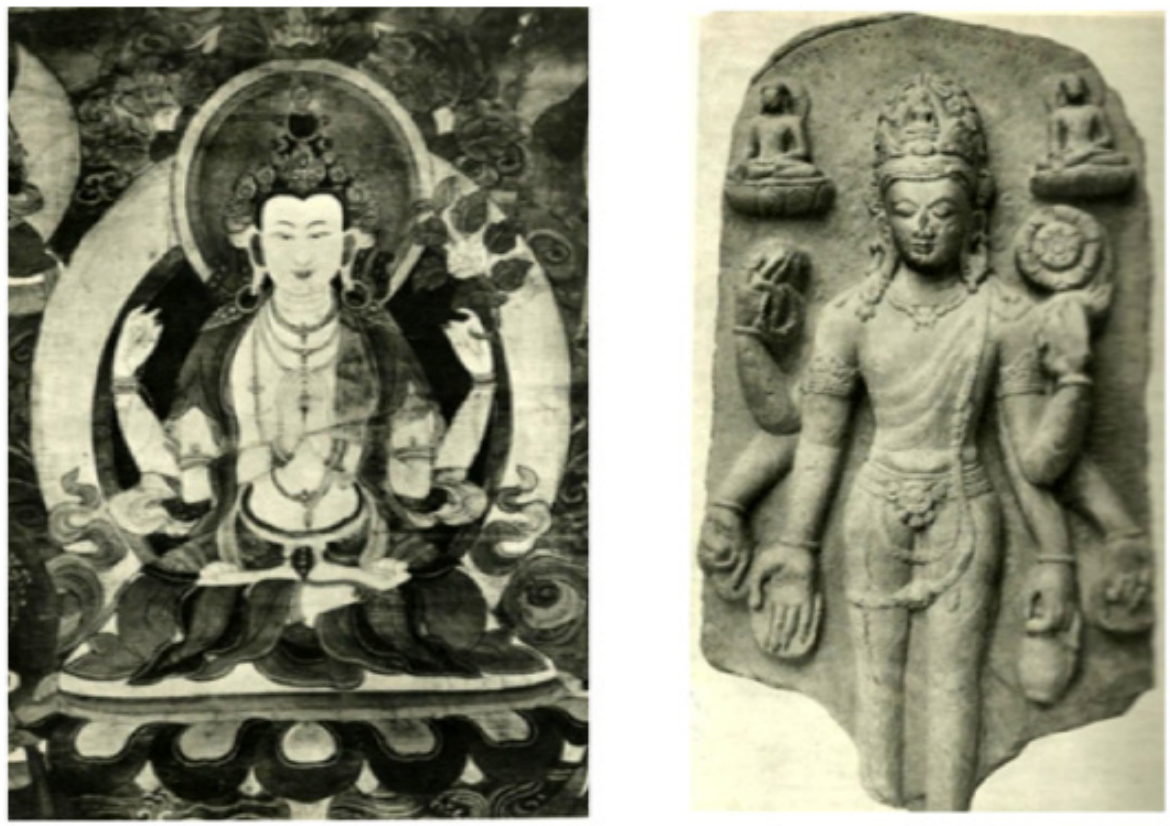

Figura 4-Imagens da divindade Avalokiteçvara presentes no livro Mythologie générale, p. 332 e 334

Já em uma nota de planejamento do romance, Osman Lins fez uma caracterização da divindade Avalokiteçvara, e a descrição condiz com o que se tem na entrevista, sem falar que ele expôs claramente a página 332 de Mythologie générale como fonte das informações. Dessa maneira, mesmo não fazendo parte da biblioteca preservada, pode-se considerar a relevância do livro no processo de criação de Avalovara, uma vez que a ligação se estabelece a partir da folha de rosto conservada e dos rastros na nota, componentes que viabilizam com maior segurança o cotejo com o texto matriz ${ }^{29}$.

29 Mesmo Osman Lins apresentando abertamente a origem do nome da obra, nunca ficou explícito qual a fonte de sua pesquisa. Nesse sentido, fiz essa investigação em dois momentos, sendo o primeiro por meio da transcrição e análise da nota de planejamento do romance, reflexão que se encontra na minha dissertação de mestrado. PEREIRA, Eder Rodrigues. A chave de Jano - os trajetos da criação de Avalovara, de Osman Lins: uma leitura das notas de planejamento à luz da crítica genética. Dissertação (Mestrado em Teoria Literária e Literatura Comparada). Faculdade de Filosofia, Letras e Ciências Humanas, Universidade de São Paulo, São Paulo, 2009, 309f., p. 228-23I. Já o segundo ocorreu quando localizei a folha de rosto do livro Mythologie générale, permitindo assim entrar em contato com imagens da divindade Avalokiteçvara e o texto que serve de base para a nota de planejamento. Assim, foi possível recompor o trajeto de criação do nome do romance, ideia elaborada em: PEREIRA, Eder Rodrigues. Da leitura à escritura - a biblioteca de Osman Lins como parte do processo criador de Avalovara. Tese (Doutorado em Teoria Literária e Literatura Comparada). Faculdade de Filosofia, Letras e Ciências Humanas, Universidade de São Paulo, São Paulo, 20I5, 589f. 


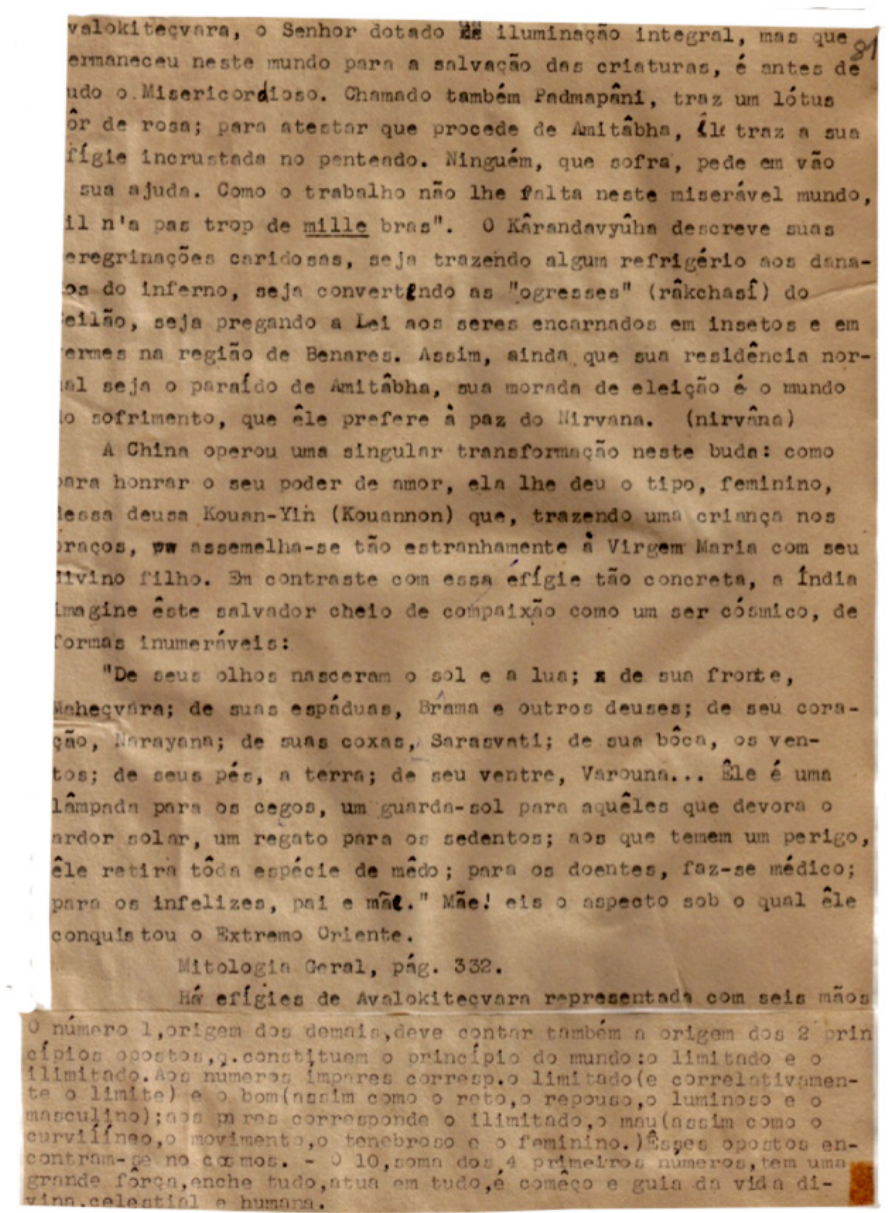

Figura 5 - Indicação da página 332 de Mythologie générale como fonte da imagem da divindade Avalokiteçvara

Mas vale ressaltar que não se deve enxergar esta vertente de análise como "um método de apoio para enriquecer o estudo das "fontes" e a abordagem biográfica da obra"30, trata-se antes de tudo de um limiar entre os materiais preexistentes e a escritura literária. Devido a isso, há condições de direcionar o ponto de vista sobre o fenômeno de captura e integração, observando ainda o modo como se manifesta o processo de seleção e apropriação bem como os mecanismos de produção e transformação. Portanto, se por um lado existe a dificuldade de recomposição do que se perdeu da biblioteca, por outro, os rastros remanescentes guardam os elementos

30 BIASI, Pierre-Marc de. A genética dos textos. I. ed. Trad. Marie-Hélène Paret Passos. Porto Alegre:

EdiPUCRS, 20I0, p. 29. 
recônditos nos documentos do arquivo onde se estratificam alguns volumes ou até mesmo verdadeiras "estantes declaradas"

Com isso, é possível ver quais livros fizeram parte do universo de interesse do escritor, sem falar no fato de que na citação de determinada obra abre-se um caminho para estabelecer relações com materiais exteriores, indicando assim alguns trajetos das operações de absorção, do modo como se constrói o empréstimo ou simplesmente o exercício da leitura. Nessa direção, ao examinar as diversas cartas escritas pelo autor entre I944 e I978, além das impressões e confidências pessoais espalhadas por esse material, recompõem-se outras leituras por meio das citações, referências e breves análises de obras literárias.

Um apoio a essas considerações está na correspondência com a poetisa Zila Mamede $^{32}$, cartas em que os assuntos pontuam análises dos livros dela, Rosa de pedra (I953) e Salinas (I958), trabalho cuidadoso do crítico33. Osman Lins comenta poemas, avalia aspectos formais, temáticos e pontua a evolução da poesia da amiga:

[...] Há, sem dúvidas, poemas ruins ou quase isso. Mas quem é que publica um livro só de poemas bons? Nem sempre, Zila, o poeta está na obrigação de fazer poemas bons. Ele tem o direito de cometer os seus erros, de fazer o que é pessoal, de satisfazer caprichos. Há mesmo as ocasiões em que ele deve fazer má poesia. Aqui para nós: sofro, às vezes, uma espécie de inquietação, quando me lembro da rigorosa métrica, da perfeição formal com que Mauro Mota compôs as suas Elegias. É um problema que me preocupa, este do decoro com que o escritor deve tratar determinados temas, o da morte principalmente [...].

[...] sobre a tua poesia, creio que só uma coisa é preciso reafirmar: és, inevitavelmente, um poeta. E cresces, cada vez mais, nos teus versos novos. Agora, segundo sinto, as hesitações vão passar. Tudo o que era solicitação alheia à tua vontade será eliminado. A tentação de seguir a moda, de fazer como os outros, ou mesmo de não fazer como os outros, tudo isso está passando. Zila, que se adivinhava, está se encontrando. E será - muito breve - uma das grandes vozes do Brasil. A primeira voz de mulher, na poesia brasileira, com odor de terra. Pois, até hoje, só tivemos poetisas civilizadas.

Veja você, é engraçado como nos enganamos. Dizia você:

3I Pensando em alguns conceitos desenvolvidos no livro $O$ trabalho da citação, de Antoine Compagnon, em especial a ideia de que toda citação configura-se como uma espécie de leitura, elaborei um índice onomástico de autores, artistas, personalidades e obras a partir das citações diretas feitas por Osman Lins em seus livros. COMPAGNON, Antoine, op. cit. Acredito que esse "catálogo" indica outras referências que provavelmente passaram pelas mãos do autor. Ver: PEREIRA, Eder Rodrigues, 20I5, op. cit., p. 50I-579.

32 Zila Mamede (I928-I985) nasceu em Nova Palmeira, Paraíba, mas viveu e desenvolveu seu trabalho no Rio Grande do Norte. Atuou como bibliotecária e na produção poética: as obras Rosa de pedra (I953), Salinas (I958), O arado (I959), Exercício da palavra (I975) e Corpo a corpo (I978) foram reunidas no livro Navegos (I978), dedicado à memória de Osman Lins.

33 Comentários sobre os poemas do livro Rosa de pedra, carta de 26 de novembro de I953. Fundo Osman Lins IEB/USP - Documento: OL-RS-CA-ooo2. 
Nunca serei nossas terras,

Que só existo no mar.

E, no entanto, é na terra que você irá encontrar a sua salvação. O mar, para você, talvez não fosse mais do que o símbolo da sua procura da viagem em busca de si mesma [...] ${ }^{34}$.

Já na correspondência com Lauro de Oliveira em que predominam questões pessoais e familiares, interessa é o diálogo sobre leituras no que aparecem José Lezama Lima e o romance Paradiso, além de exaltar Jorge Luís Borges e sua produção literária35.

Assim, nesse material encontra-se parte de uma história literária à espera de decifração, sem falar que relacionada ao processo criativo essa correspondência "pode revelar matrizes e circunstâncias da escritura, documentar lições elididas na versão de um texto publicado (e, eventualmente, conter a justificativa das escolhas realizadas), acolher projetos artísticos nascidos ao correr da pena [...]" ${ }^{36}$. Além disso, muitos outros aspectos das prováveis leituras realizadas por Osman Lins e a dispersão de certas obras estão em outros documentos do arquivo.

Em um recibo da Livraria José Olympio de 28 de janeiro de I953, há o registro de compra de uma coleção com I5 volumes das Obras completas e ilustradas, de Dostoiévski, mas os livros não estão presentes na biblioteca de Osman Lins da Casa de Rui Barbosa ou do IEB/USP. Em outro documento, um cartão de sócio usuário da biblioteca do Instituto Goethe, encontra-se a retirada em 26 de maio de I977 de um livro de Thomas Mann. Logo, esses registros pontuam dois momentos diferentes e acentuam que a busca do conhecimento não se restringe apenas a um espaço privado, sendo possível pensar que outras bibliotecas contribuíram para a formação de Osman Lins.

Nessa direção, Elisabete Marin Ribas nos mostra que no período em que Osman Lins foi professor de Literatura Brasileira na Faculdade de Filosofia, Ciências e Letras

34 Comentários sobre o livro Salinas, carta de I5 de dezembro de I958. Fundo Osman Lins IEB/USP Documento: OL-RS-CA-ooIo.

35 Durante o ano de 20II, organizei parte da correspondência ativa e passiva do Fundo Osman Lins IEB/USP. Nesse conjunto de cartas percebem-se determinadas lacunas, uma vez que a ausência de algumas interrompe o fluxo do diálogo. Isso ocorre, aparentemente, por dois motivos: certos documentos estão depositados na Casa de Rui Barbosa e outros estão provavelmente com os destinatários. No geral, as cartas de Osman Lins tratam de assuntos diversos e dispersos, aspectos que impedem a construção uma unidade de interesse literário. Porém, no diálogo que ele estabelece com Zila Mamede, Alexandrino E. Severino, Lauro de Oliveira, Laís Corrêa de Araújo e o já mencionado Hermilo Borba Filho, há a possibilidade de construir esse objeto de estudo, pois são frequentes os comentários sobre obras, questões literárias, traduções e reflexões sobre o painel cultural do período. Com isso, uma investigação em torno da correspondência de Osman Lins com esses amigos se faz necessária para que tais cartas não desapareçam com o tempo e também para dar atenção a esses interlocutores.

36 MORAES, Marcos Antonio. Ligações perigosas. In: PINO, Claudia Amigo (Org.). Criação em debate. I. ed. São Paulo: Humanitas, 2007, p. 73. 
de Marília, ele dedicou parte do curso à Arte Dramática, e no arquivo dele há um conjunto de 44 documentos relacionados à teoria teatral. Assim, Ribas observa a incongruência e a minúcia dos títulos para um curso de Letras, relacionando esse material ao curso de dramaturgia seguido por Osman Lins na Escola de Belas Artes da Universidade do Recife. Com isso, além da presença de um conteúdo que advém de outro espaço, ela indica várias referências existentes nos documentos, como Aristóteles, Platão, Heráclito, Homero, Sófocles, Parménides, Hegel, Kant, Bergson, Hobbes, Nietzsche, Schopenhauer, São Tomás, Santo Agostinho, Shakespeare, Brecht, Henrik Ibsen, Stendhal e Dostoiévski37.

Nesse sentido, pode-se afirmar que, nessa ampla rede de referências, a prática de leitura de Lins tem vida própria, sendo que suas "leituras se sucedem, mas nem sempre se assemelham; elas se influenciam, modificam, agem sobre o leitor, levado a desviar seu trajeto à mercê de seus encontros e de seus desejos", conforme apresentam Chantal Horellou-Lafarge e Monique Segré em sua Sociologia da leitura ${ }^{38}$. Assim, pode-se ver a "biblioteca declarada" de Osman Lins como um verdadeiro labirinto desenhado pela rede de citações de obras e autores no texto do romancista, elementos que são deslocados de sua integralidade para fazer parte de um novo contexto.

Contudo, Osman Lins entendeu como poucos que, mesmo existindo a possibilidade de escolhas, um livro só se revela a quem o toma entre as mãos e, página após página, procura penetrar o seu conteúdo. É, portanto, na necessidade de buscar novos caminhos e abordar novas experiências, não somente do ponto de vista temático, mas também estrutural, em termos estéticos, que ele traz parte de suas leituras para inovar sua arte de narrar.

SOBRE O AUTOR

EDER RODRIGUES PEREIRA é doutor em Teoria Literária e Literatura Comparada pela Faculdade de Filosofia, Letras e Ciências Humanas da Universidade de São Paulo (FFLCH/USP). Pós-doutorado em andamento no IEB/USP, com supervisão da profa. dra. Telê Ancona Lopez, sobre o romance Noite profunda/ Os espelhos, obra inédita de Osman Lins.

E-mail: ederrodriguespereira@yahoo.com.br

37 RIBAS, Elisabete Marin, op. cit., p. 58-63.

38 HORELLOU-LAFARGE, Chantal; SEGRÉ, Monique. Sociologia da leitura. I. ed. Trad. Mauro Gama. São Paulo: Ateliê, 20IO, p. I24. 


\section{REFERÊNCIAS BIBLIOGRÁFICAS}

ANTELO, Raul. Labirintos da biblioteca do pobre. Outra travessia, $\mathrm{I}^{\circ}$ semestre de 2015.

BELLOTTO, Heloísa Liberalli. Arquivo: estudos e reflexões. Belo Horizonte: UFMG, 2014.

BENJAMIN, Walter. Desempacotando a minha biblioteca. In: . Rua de mão única. I. ed. Trad. João

Barrento. São Paulo: Autêntica, 2013.

BIASI, Pierre-Marc de. A genética dos textos. I. ed. Trad. Marie-Hélène Paret Passos. Porto Alegre: EdiPUCRS, 2010.

COMPAGNON, Antoine. O trabalho da citação. I. ed. Trad. Cleonice P. B. Mourão. Belo Horizonte: Editora UFMG, 2007.

DERRIDA, Jacques. Mal de arquivo - uma impressão freudiana. I. ed. Trad. Claudia de Moraes Rego. Rio de Janeiro: Relume-Dumará, 2001.

DURANTE, Erica. La biblioteca de escritor frente al mundo global: repensar un método a partir de R. Piglia, D. Link y R. Fresán. Manuscrítica - revista de crítica genética, São Paulo, n. 24. 2013.

ELIADE, Mircea. O sagrado e o profano. 5. ed. Trad. Rogério Fernandes. São Paulo: Martins Fontes, 2001. FERREIRA, Ermelinda Maria Araújo. Cabeças compostas - a personagem feminina na narrativa de Osman Lins. 2. ed. São Paulo: Edusp, 2005.

GOLDFARB, Ana M. A. Da alquimia à química. I. ed. São Paulo: Nova Stella-Edusp, I987.

GOULEMOT, Jean Marie. O amor às bibliotecas. I. ed. Trad. Maria Leonor Loureiro. São Paulo: Editora Unesp, 2010.

GRÉSILLON, Almuth. Ler para escrever. Escritos - Revista da Fundação Casa de Rui Barbosa, ano 5, n. 5, $20 I I$.

GUIRAND, Félix (Dir.). Mythologie générale. I. ed. Paris: Librairie Larousse, I935.

HORELLOU-LAFARGE, Chantal; SEGRÉ, Monique. Sociologia da leitura. I. ed. Trad. Mauro Gama. São Paulo: Ateliê, 2010.

LIMA, Luiz Costa (Org.). A literatura e o leitor: textos de estética da recepção. Rio de Janeiro: Paz e Terra, I979. LINS, Osman. Evangelho na taba - outros problemas inculturais brasileiros. I. ed. São Paulo: Summus Editorial, I979.

LOPEZ, Telê Ancona. A criação literária na biblioteca do escritor. Ciência e cultura, revista da SBPC, v. 59, n. I, jan.-mar. 2007.

. Os manuscritos no arquivo e na biblioteca de Mário de Andrade. In: NITRINI, Sandra (Org.). Tessituras, interações, convergências. I. ed. São Paulo: Hucitec/Abralic, 20II.

MORAES, Marcos Antonio de. Ligações perigosas. In: PINO, Claudia Amigo (Org.). Criação em debate. I. ed. São Paulo: Humanitas, 2007.

MOURA, Ivana. Osman Lins: o matemático da prosa. I. ed. Recife: Fundação de Cultura do Recife, 2003. PEREIRA, Eder Rodrigues. A chave de Jano - os trajetos da criação de Avalovara, de Osman Lins: uma leitura das notas de planejamento à luz da crítica genética. Dissertação (Mestrado em Teoria Literária e Literatura Comparada). Faculdade de Filosofia, Letras e Ciências Humanas, Universidade de São Paulo, São Paulo, 2009, 309f.

. Da leitura à escritura - a biblioteca de Osman Lins como parte do processo criador de Avalovara. Tese (Doutorado em Teoria Literária e Literatura Comparada). Faculdade de Filosofia, Letras e Ciências Humanas, Universidade de São Paulo, São Paulo, 20I5, $589 \mathrm{f}$.

RIBAS, Elisabete Marin. Giz, caneta e pincel: literatura e história da arte nas aulas do professor Osman Lins. Dissertação (Mestrado em Teoria Literária e Literatura Comparada). Faculdade de Filosofia, Letras e Ciências Humanas, Universidade de São Paulo, São Paulo, 20I2, I94f. 
RIBEIRO, Renata Rocha. Leitura e escrita na narrativa de Osman Lins. Tese (Doutorado em Estudos Literários). Faculdade de Letras, Universidade Federal de Goiás. Goiânia, 20Io, $269 f$.

SALLES, Cecília Almeida. Redes da criação - construção da obra de arte. I. ed. São Paulo: Horizonte, 2006. SOARES, Marisa Balthasar. No arquivo do artesão. Cult, julho de $200 \mathrm{I}$.

SEDLMAYR, Hans. A revolução da arte moderna. I. ed. Trad. Mário Henrique Leiria. Lisboa: Livros do Brasil, I955. 